\title{
A ENTREVISTA COMO MÉTODO: UMA CONVERSA COM EDUARDO COUTINHO
}

\section{Fernando Frochtengarten}

Resumo: O nome de Eduardo Coutinho ocupa páginas centrais na história do cinema documentário brasileiro. Conhecido pelas entrevistas com pessoas anônimas, seus filmes revolucionaram a produção no gênero: ajudaram a derrubar o mito da neutralidade dos documentários e desfizeram a separação entre o diretor e os personagens. As transformações que sua obra imprimiu no campo estético e epistemológico próprios ao cinema têm afinidades com as mudanças de paradigmas experimentadas pelas ciências humanas no século passado. Este artigo apresenta uma entrevista com Eduardo Coutinho. Nela, o cineasta discute a concepção do real presente em seus filmes e o poder de transformação do cinema sobre os homens e a sociedade; principalmente, fala sobre as entrevistas, método em evidência nas ciências humanas e no cinema.

Palavras-chave: Entrevista. Cinema. Etnografia. Psicologia social.

\section{Preâmbulo}

O panorama histórico e o atual quadro de produções do cinema documentário brasileiro são indissociáveis do nome de Eduardo Coutinho. Diretor de filmes como Cabra marcado para morrer, Santo Forte, Edifício Master e Peões (ver filmografia completa ao final desse artigo), sua marca essencial são as entrevistas que realiza com pessoas anônimas. Seus documentários são compostos por uma sucessão de entrevistas após as quais caem os letreiros. Nada mais.

Podemos entrever alguma comunidade entre os entrevistados de cada um dos filmes de Eduardo Coutinho. Ainda que frequentemente não se conheçam, os personagens são amarrados pela coabitação de uma geografia, pelo exercício de um mes- 
mo trabalho ou pela coparticipação em acontecimentos pregressos. Porém, é tênue essa comunhão. Ela circunscreve um campo de experiências humanas sem que as singularidades de cada ser humano sejam apagadas por teses generalizantes sobre as condições compartilhadas. No lugar de uma racionalidade que amarrasse as entrevistas a um fio lógico necessário e produzisse categorias (o catador de lixo, o sertanejo ou o operário), os filmes garantem lugar à unicidade das formas como este catador de lixo, este sertanejo ou este operário tomam o mundo para si (Lins, 2004).

As histórias dessas pessoas nos chegam através de entrevistas feitas pelo próprio cineasta que, acompanhado de sua equipe, aparece nas imagens. A explicitação do método pelo diretor-personagem insiste em lembrar que o cinema é transformador da realidade retratada. E que o filme que ora assistimos é uma representação do real.

Sob esses dois aspectos - a saber, o tratamento dado pela montagem às entrevistas e a transparência de seu método - a obra de Eduardo Coutinho revolucionou o modo de fazer documentários que predominou nos anos 1960 e 70. Os filmes dessa época, alinhados a um "modelo sociológico" (Bernardet, 2003), se caracterizam pela locução de um narrador invisível que é o dono da voz. Em terceira pessoa, ele fala sobre personagens que só comparecem quando chamados, a fim de servirem como exemplos que confirmem as teses apresentadas pela narração. A diluição dos personagens em uma catalogação de tipos sociológicos facilita os encadeamentos que os filmes querem fazer soar naturais ao espectador. $O$ documentário quer coincidir com o real: o dono da voz quer ser também o "dono do mundo".

O cinema de Eduardo Coutinho escancara o caráter de discurso que os documentários "sociológicos" se esforçavam por ocultar. Sobretudo porque seus filmes não falam de fora, mas de dentro da relação do cineasta com os personagens que retrata. É desfeita a distância entre sujeito e objeto do conhecimento que legitimava o saber dos primeiros documentários e que ainda impregna o espírito de parte da produção do gênero. Mais radicalmente, Eduardo Coutinho não filma para produzir conhecimento no sentido conceitual. Ele apenas mostra rostos e vozes que "são livres para não caber nos limites das sínteses" (Salles, 2004). A própria ausência de triIha sonora reforça esse sentido, à medida que o som de fundo ameaça instaurar uma atmosfera emocional ditada pela montagem.

A ruptura gerada pelo trabalho de Eduardo Coutinho no âmbito estético e epistemológico do cinema documentário é análoga às transformações experimentadas pela etnografia a partir do surgimento da antropologia interpretativa (Silva, 2005).

Os primeiros estudos antropológicos, datados do final do século XIX, eram feitos à distância. Os pesquisadores se dobravam sobre informações sobre povos longínquos trazidas por outros viajantes. Não tardaria, entre- 
tanto, para que o trabalho de campo fosse consagrado como método primaz de uma etnografia moderna'.

Em suas expedições rumo à Oceania, à Ásia e à África, os primeiros etnógrafos levavam consigo o pressuposto de um desnudamento dos códigos e valores de sua cultura. $\mathrm{O}$ aval científico ao saber etnográfico presumia um apagamento da figura do estudioso forasteiro, o que permitiria seu acesso sorrateiro ao real. $O$ etnógrafo despojado pensava-se liberto da suposta ameaça de interferir sobre a realidade que desejava conhecer. A relação com o outro, portanto, não merecia consideração como parte das condições geradoras do conhecimento.

A superação dessa concepção de inspiração positivista ganharia vigor com o conceito semiótico de cultura adensado, nos anos 1970, pela antropologia de Clifford Geertz. A cultura passava a ser pensada como um texto cujo significado cabia ao etnógrafo interpretar. Não no sentido de alcançar uma verdade definitiva contida no outro, mas de traduzir para um discurso próprio as interpretações que somente um nativo pode fazer em primeira mão sobre sua própria cultura. Ao etnógrafo só seria possível interpretar uma outra cultura por sobre os ombros do nativo. $O$ saber então produzido deixava de equivaler à expressão do real para converter-se em uma construção feita pelo etnógrafo. Sua inserção, observações e escrita assim ingressavam no campo de interesses da disciplina. E seu texto, ora experiência do pensamento, se aproximava da ficção (Geertz, 1989).

No campo da Psicologia Social brasileira, cuja vertente qualitativa incorporou elementos do método etnográfico, a realização de entrevistas freqüentemente integra o regime de longa participação do pesquisador em meio aos sujeitos que absorvem seu interesse. Aliadas às observações e às conversas desinteressadas de convivências duradouras, as entrevistas promovem o ingresso do pesquisador em uma relação de compromisso com o outro. Não terá sido por acaso que a noção de comunidade de destino, que pressupõe um deslocamento para a perspectiva do outro sujeito, acompanhado por um sofrimento irreversível de sua condição, nos tenha chegado e sido esclarecida pelas mãos de psicólogos sociais cujos trabaIhos tanto prezam as entrevistas (Bosi, 1995; Gonçalves Filho, 2003).

O declínio do mito da neutralidade descolou psicólogos sociais, etnógrafos e cineastas de uma posição de exterioridade relativa àqueles homens a quem mira o foco de sua atenção. E converteu as ciências humanas e o cinema documentário em experiências radicais da alteridade.

A entrevista com Eduardo Coutinho apresentada a seguir foi realizada no cair de uma tarde de junho de 2007, no Centro de Cinema Popular no Rio de Janeiro. Tomando como eixo central as entrevistas e seu relacionamento com os entrevistados, discute as concepções do real contidas em

1 Para a afirmação do trabalho de campo, muito colaborou a longa permanência de Bronislaw Malinowski na Nova Guiné e a publicação, em 1922, do estudo resultante, Argonautas do Pacífico Ocidental. 
seus filmes e seu poder de transformação sobre os homens e a realidade social.

\section{Entrevista}

O sr. costuma afirmar que seus filmes não são compostos por entrevistas, mas por conversas. Poderia falar um pouco sobre a preferência por este termo?

Se há uma coisa que acho que aprendi, por razões obscuras, é conversar com os outros. Com câmera, porque sem câmera eu não falo com ninguém.

A maioria dos que fazem documentários fazem, efetivamente, entrevistas. As entrevistas têm um lado jornalístico e de depoimento. Entrevistas e depoimentos são coisas para a História. São coisas que se fazem com especialistas. E eu trabalho com pessoas comuns. A pessoa conta um fato histórico e, se ele é verdadeiro ou não, deixa de ter importância.

As conversas são conversas porque falo com pessoas anônimas - ninguém é anônimo, mas enfim... - relativamente comuns, ordinárias no sentido antigo do termo. Têm pouco a perder e por isso são interessadas. Um intelectual ou um político de esquerda ou direita têm muito a perder. Então eles se defendem. Eas pessoas mais comuns têm pouco a perder. Talvez na vizinhança. Essa é a primeira razão pela qual as pessoas ditas comuns são mais interessantes.

A segunda coisa é que, em geral, elas falam a partir da vida privada. Eo que é a vida privada? O que é a vida, no fundo? Pra mim é muito simples e, em certo sentido, complicado. Todas as pessoas nascem, vivem e morrem. E, aliás, infelizmente, sabem que vão morrer. O animal não sabe. E se o animal falasse me interessava. E nesse espaço que você não sabe quanto vai durar, tem uma vida que, pode ser intelectual ou camponês, é muito próxima uma da outra: uma origem que é familiar, étnica, cultural, religiosa ou de classe. E fora isso é tão simples: amor, sexo, casamento, filhos, dinheiro, saúde e aí chegamos à questão da morte. Isso é o núcleo que me interessa. E nele podem estar Lênin ou São Francisco de Assis, com todas as suas utopias e sonhos. E dentro disso eu não tenho que checar nada.

No [Edifício] Master, uma mulher me disse:"Vivi com um alemão por dez anos".Eu não vou checar se foram dez ou cinco anos ou se ele era argentino. Eu perguntei se ela foi feliz e ela disse que foi. É o que me importa. Naquele presente é verdadeiro. O passado não me interessa, eu não vou pesquisar. Só não me interessa a mentira do mitômano, que é um belo assunto de filme, mas que factualmente não tem sentido. Fora isso a memória é, para mim, a coisa mais mentirosa do mundo. O que não quer dizer que não seja verdadeira. Você me conta sua infância de um jeito como você a conhece hoje. Se eu for te procurar daqui a um ano você vai me dizer de outro jeito. 
Essa questão do verdadeiro e do falso é resumida no Master por uma garota de programa que me disse: "Eu sou uma mentirosa verdadeira". Ela achou que tinha uma avó que tinha morrido. Mas achou tanto que passou a ser verdade para ela. Como no livro "Assunção de Salviano", do [Antônio] Callado, sobre um cara que é escolhido para ser santo, para fazer milagre, e depois de um tempo ele passa realmente a acreditar que é santo. É por isso que se produzem milagres.

A partir disso tem uma questão que eu considero espiritual. Eu trabalho na incerteza, na ignorância. Porque eu não sei o que é a vida do outro. Eu posso ter mil teses antropológicas, como no caso de Santo Forte. Às vezes eu sei aonde eu vou chegar. Mas como eu vou chegar eu nunca sei. O que interessa são as digressões, hesitações, retomadas de texto, gaguejadas, lapsos extraordinários.

E tem uma questão ridícula que muita gente fala: "Você põe a câmera e a pessoa muda". $O$ [Jean] Rouch ${ }^{2}$ dizia, há trinta ou quarenta anos, contra o cinema direto americano, que a presença da câmera não era escondida e produz um "efeito câmera" em que a pessoa se constrói, faz uma performance, $e$ que isso é tão importante quanto o fato dela não fazer essa performance. Por isso não dá para julgar se é mentira. A pessoa se reinventa a partir do que ela acredita.

Há vinte anos se fazia documentários no Brasil em que o diretor não tinha nem microfone. Quer dizer, era admissível que a pergunta dele não interferisse. Em toda minha experiência de vida e de filmagem eu vi que, não importa se há pesquisa anterior e se eu conheço alguns fatos, o acaso está sempre presente. Eque há um problema que é saber quando perguntar, o quê perguntar, quando romper o silêncio e quando não romper. Eu estou a toda hora errando. Porque o documentário é baseado na possibilidade de erro humano. Até hoje acontece de eu perguntar na hora em que eu não devia e o silêncio acaba. Ou eu faço a pergunta errada. Às vezes eu consigo fazer a pergunta certa. Tudo porque a voz em um filme ou na história oral é imediata.

$O$ [Roland] Barthes diz que existe a fala e a escrita e, entre os dois, a transcrição, que é a castração da fala. É quando você tira a carne. Uma das coisas é fazer legenda para filme ou transcrever. A pessoa não fala vírgula, não fala ponto, não fala entre parênteses. Você tenta dar uma ordem para a fala com sinais gráficos, mas tem que ter cuidado para não destruí-la. No Pasquim, que renovou a entrevista no Brasil, quando o entrevistado dizia uma coisa vinha entre parênteses "risos." Isso se usa muito até hoje e é a coisa mais odiosa. O corpo você perde e para isso não há solução. Existe um artigo do Ismail Xavier, na Cinemais, em que ele fala dos filmes com entrevistas ${ }^{3}$. Ele pega o meu caso, em que só tem entrevistas e, geralmente, sem uma volta. Enquanto em toda a tradição do cinema clássico há uma progressão histórica do herói que se lasca ou vence. Os meus filmes são inteiramente de entrevistas. A câmera não se

2 Documentarista e etnógrafo francês (1917-2002).

3 Xavier, I. (2003). Indagações em torno de Eduardo Coutinho. Cinemais, 36, 221-235. 
mexe de lugar e não se corta nunca. Não tem interrupção. E como as pessoas agüentam ver? Tem o "efeito câmera": a pessoa sabe que tem uma câmera, eu não escondo, mas de fato você nunca sabe exatamente quando ela está consciente da câmera ou não está.

$O$ acaso, a surpresa e a incerteza do resultado é que me interessam. Eu acho que as relações dão certo quando não são pergunta e resposta, mas um ato colaborativo. O ato de filmagem é assim: a pessoa me diz alguma coisa que nunca vai repetir, nunca disse antes ou dirá depois. Surge naquele momento. $E$ isso não é pingue-pongue. As pessoas interagem comigo. Um português me contou que foi ver Santo Forte e de repente sentiu que as palavras saíam de um "entre lugar" que não existe na entrevista típica. Eu uso essa técnica de que a câmera existe, mas fica no lugar dela; a pessoa fica confortável, pode se mexer, atender o telefone. Mas ela dificilmente vai saber o que eu quero dela. Por exemplo, dos intelectuais que vão a um lixão, noventa por cento vão para pegar gente que fala mal do governo, que isso é uma vergonha, etc. E eu fui fazer o filme em um lixão e usei uma pergunta absolutamente obscena: "Aqui é bom ou mau?". Tem gente que ficou maluca. Mas no filme tem pessoas que dizem que é melhor do que trabalhar em casa de madame. Porque no momento em que você tipifica e desqualifica o outro, que você diz "o lixo é um inferno e esse cara é um abutre", ele não tem como se doar com um certo nível de igualdade utópica. Outro caso é dos cineastas que vão entrevistar um analfabeto na Amazônia e, em cinco minutos, ele sabe o querem que ele diga. Isso mata.

Veja o caso do Master, em que uma mulher me diz que todo brasileiro é preguiçoso. É um discurso com o qual eu não concordo. Mas é um discurso extraordinário porque ela teve condições de dizer aquilo para mim. E eu não estou lá para dizer "a senhora está errada". O discurso é magnífico porque são as razões dela, não são as minhas. Ela acredita naquilo que está falando e fala com veemência.

Eu não me interesso em filmar os objetos, a casa da pessoa, em detalhar a condição social. O que me interessa é um rosto que fala. Existem filmes em que, para cortar, mostram um cachorro no chão, um quadro na parede. Nos meus filmes, não. As pessoas falam com o verbal e com o gestual. Quando as conversas rendem, têm uma qualidade poética tão grande que qualquer tipo de ilustração é empobrecimento. Tem filmes em que a pessoa diz "Eu trabaIho em um banco" e então ele aparece trabalhando. Você vai provar o quê? Que aquilo é real? Isso é absolutamente banal, totalmente inútil. Se botar essa imagem, ela vira um conceito que aprisiona. As filigranas do discurso é que são o real. Então eu tenho que ter uma grande fé na possibilidade da palavra. Sobre isso existe um artigo do [Pierre] Bourdieu - que é uma pessoa admirável e que eu detesto, porque ao mesmo tempo é um racionalista, materialista, determinista - no livro A miséria do mundo. Eu joguei fora o livro e fiquei com as dez páginas sobre a entrevista, que também não sei se perdi. Ele fala que o problema é ouvir o outro em condições em que ele nunca é ouvido, é tentar se 
colocar no lugar do outro, ver de que lugar o outro fala aquilo que é visceral e não opinião.

Nos filmes que eu faço, tento me colocar entre paredes e produzir um vazio que o outro tem que preencher. Muita gente pergunta se eu não sinto culpa por isso. Eu faço isso sem culpa nenhuma. Eu faço tudo com culpa na minha vida. Mas filmar e conversar com as pessoas eu faço sem a menor culpa. No caso do Master teve gente que disse que eu mostrei intimidade. Ou que teve gente que riu em horas que não devia. Eu não posso castrar o riso do público. Além disso, existem muitos tipos de riso. Cada pessoa é dividida, você calcula um público.Tem gente que ricom a pessoa que fala, tem gente que ri da pessoa que fala e tem o riso nervoso, de medo. Para mim, todas as pessoas que aparecem no Master não são ridículas. Ou, eu sou tão ridículo quanto elas. Aquelas pessoas são tão patéticas quanto eu.

Em um artigo escrito por ocasião do lançamento de Edifício Master, João Moreira Salles escreveu:"filmar - e principalmente, filmar documentários - modifica o mundo. Sem heroísmo, muito pouquinho, sutilmente, mas modifica. O caso do Eduardo, para melhor" (Época, 18.11.2002). Já o sr. costuma dizer que o cinema não pode resolver problemas sociais...

Não sei o contexto dessa fala do João, mas ele tem dito, muito mais do que eu, que o documentário não muda nada no mundo. Isso seria uma ilusão tola. E ele diz mais: que não muda nada nos personagens do filme. Eu concordo, em termos. No caso da Elizabeth Teixeira mudou' ${ }^{4}$ É um caso absolutamente à parte. Não fiquei amigo dela. Ela mora longe, o mundo dela é outro.

Mas em geral, eu acho que o documentário não muda a vida das pessoas. E eu tento que não mude para pior. Das pessoas que aparecem no Master, eu não soube de nenhuma que foi humilhada ou demitida. A minha honestidade com essas pessoas é fazer uma exibição particular para eles ou dar o DVD e ter a sua aprovação. Eu não quero a aprovação da classe, nem sei o que quer dizer classe. Eu fiz um filme em uma favela, mas não quero a aprovação dos favelados do Brasil. Quando eu fiz o Santa Marta [duas semanas no morro] tive um contrato com aquelas pessoas individuais que estavam lá. E, claro, com a comunidade em que eles moram. Mas mudar o mundo... eu acho que nenhum filme muda o mundo. Isso é ilusão dos anos 1960. Nas pessoas pode haver mudanças. camponês assassinado cuja história Eduardo Coutinho começou a filmar em 1964, em Pernambuco. Porém, o golpe militar e a invasão do local das filmagens pelo exército interromperam o projeto original. Em 1981, Eduardo Coutinho voltou ao Nordeste para retomar as filmagens. Reencontrou Elizabeth Teixeira e outros personagens do filme de 64. Por ocasião do lançamento de Cabra marcado para morrer, Elizabeth Teixeira saiu da clandestinidade e reencontrou alguns filhos de quem havia se separado. 
Que mudanças o sr. acha que podem ser promovidas pelo fato das pessoas serem escutadas, filmadas?

Há várias etapas. Na etapa da filmagem, tenha ou não cachê, quando as coisas funcionam, a pessoa se sente extremamente bem. E quanto mais se expõe, mais se sente bem. A filmagem é muito intensa. Veja o caso do silêncio. Tive que aprender a deixar passar e ver como a pessoa sai do buraco. A pessoa vai ao fundo dela mesma. No fim de Peões teve isso. Eu consegui, pela primeira vez, ficar sofrendo vinte ou trinta segundos, para saber como a pessoa sai de um buraco. Porque eu sempre entrava para ajudar. Eu não aguentava. Eu aguentei e foi maravilhoso porque ele saiu de uma forma absolutamente genial, perguntando, na última fala do filme: "O sr.já foi peão?".Eu fiquei absolutamente surpreso e disse o que saiu na hora: "Não". E tinha uma frase a mais que eu tirei porque matava o silêncio posterior. Eu dizia: "Não, que eu saiba".

Esse prazer do desabafo pode ser um choro, pode ser alegria, pode ser de xingar uma pessoa. Isso bate com uma coisa que o Bourdieu, que é esse cético total, fala em mais de um livro: que o essencial no ser humano de qualquer classe é ser ouvido, ser legitimado, ser justificado em sua singularidade. Nenhuma voz é igual à outra. Tem sempre uma forma original. Se não tem, nem entra no filme porque é um estereótipo. Um homem de vida apagada sente que é reconhecido na hora da entrevista.

Então vem uma segunda etapa. Eu não faço televisão. E um filme às vezes demora um ano para ficar pronto. E eu nunca fui cobrado: "O filme não fica pronto?". As pessoas esquecem, vão vivendo a vida. Depois, quando eu chamo para a pré-estreia, nem lembram mais. Eu tento saber o que cada um achou, a reação em relação ao retrato que eu fiz. Isto é, eles construíram um retrato que eu tento manter.

E tem uma terceira etapa, quando o público vê o filme. E existem surpresas que você não pode impedir e que não fui eu quem propiciei. Tinha gente que ia ver o Babilônia [2000] e se espantava como o povo era criativo. Você faz um filme extraordinário contra o racismo e o racista não vai ser mudado por este filme. Ele pode ser mudado por um conjunto de experiências que podem vir do filme muito imediatamente. Um racista convencido por um filme não existe. É o caso dos risos. Como o Brasil tem uma divisão social e quem vai ao cinema é a classe média, podem acontecer risos condescendentes e outros não. Então existe sempre um risco de estar na corda bamba.

Você falou em três etapas. Eu gostaria que você comentasse uma quarta etapa. Em Santa Marta, duas semanas no morro, uma das entrevistadas sugere: "que vocês viessem, entrevistassem a gente e tomassem alguma solução". O sr. já comentou os limites de ação do cinema. Mas qual a natureza do vínculo que se estabelece entre o sr., como entrevistador, e seus entrevistados, depois que vocês se separam? 
Existe um romantismo dos que acham que pode existir algum vínculo. Podem existir os ingênuos que pratiquem...

Isso está ligado à possibilidade do cinema provocar transformação. Eu te digo o seguinte: a gente não sabe por que faz cinema, quanto mais documentário. Então esse vínculo depois da entrevista é quase de uma má fé, de um otimismo incurável, extraordinário. Eu não tento mudar o mundo, por exemplo, mudando os personagens na filmagem. Nos anos 1960, os cineastas progressistas, já na filmagem, censuravam aquilo que não estava no preestabelecido. Tinha um ponto de partida e quando o cara quebrava a expectativa não entrava. O que me interessa é o ambíguo. Às vezes eu falo brincando, exagerando, provocando: muito mais rico é um servo que ama a servidão do que um servo que odeia a servidão. Porque é óbvio que o servo deve odiar a servidão. Mas você encontrar essa coisa oposta é uma provocação extraordinária.

Mas que poder tem um filme de mudar o mundo? Eu acho que muda o olhar de algumas pessoas. Já está bom. E ajuda a mudar o cinema. Mas depois que acabou o filme...

Veja o caso do Cabra, que filmamos na Paraíba. Eu prometi a eles: "A gente volta aqui para passar o filme". A gente voltou exatamente um ano depois, passou três dias por lá, fez a exibição para quatrocentas pessoas. Para mim era cumprimento de um pacto. E eu sei que dificilmente eu voltarei a São João do Peixe, encontrarei vivas aquelas pessoas ou estarei eu vivo. Então foi uma despedida.

Nos casos em que eu filmo aqui no Rio, ou mesmo em Peões, eu simplesmente costumo dizer, com algum humor negro, que eu não volto ao local do crime. Eu volto, digamos, ao Master. Às vezes eu como perto dali. Eu posso encontrar uma ou outra pessoa, mas eu vou encontrar a rotina. É mentira que o documentário é tão verdadeiro quanto a rotina. A rotina é insuportável. $O$ personagem é um condensado. Há personagens absolutamente maravilhosos, mas você não convive 24 horas com eles. Em O fim e o princípio tinha uma pessoa com uma fala espantosa. Foi bom para o filme, mas em vinte-equatro horas ele me esmagava.

Não vejo sentido em ficar amigo. De vez em quando eu encontro com os personagens. Outro dia encontrei com a Cida, que é personagem do Babilônia, em Copacabana. Depois do filme, só encontro por acaso. Porque é falso. Eu não vou à casa de quase ninguém, tenho poucos amigos. Então qual o sentido?

Tem um outro elemento que já me aconteceu, mas é raro. Conheço duas pessoas que foram filmadas no Master, gostaram do filme, mas dizem que ganhamos dinheiro às suas custas. Porque o filme ficou quinze semanas em cartaz e eles acham que deu dinheiro. Eu te conto: o Master deu 85 mil espectadores, um resultado extraordinário, e pagou só o lançamento. Então, uma vez telefonou um personagem dizendo que estava desempregado e achava que a gente ganhou dinheiro com o filme. Então, quando você filma pessoas que são pobres, claro que você pode intervir, mas não mudar a sorte delas. 
O que sou é extremamente agradecido pelo fato dessas pessoas terem conversado comigo. E eu espero que eles, quando encontrem alguém da comunidade que os viu, os tenha em boa conta. Éo que espero.

A partir dessas colocações, depreendo que o sr. não vê diferenças entre filmar universos estranhos ou familiares ao seu.

Veja bem, o documentário nasceu com várias maldições. A palavra "documentário" é infeliz, a palavra "documento" é infeliz, a palavra "didático" é infeliz. Para muita gente, documentário é para ensinar, educar. Isso é uma tragédia. A National Geographic tem a sua função, mostra a vida dos peixes, a vida de Cleópatra. No que eu faço não tem nada disso. Eu não estou interessado no grande tema. O que é O fim e o princípio? É um filme para denunciar o latifúndio? O que eu encontrei foi um repositório de mitos, de sintaxes e de vocabulário que reflete um mundo patriarcal que acabou.

Perguntam muito por que eu só filmo os excluídos. Mas eu achei ótimo fazer um filme como o Master, sobre a classe média baixa. Eu tento desconsiderar o problema da classe ou da categoria à qual a pessoa pertence e fazer filmes que não sejam estereótipos. Então, se eu filmo em uma favela ou gente pobre no Nordeste, que são universos afastados do meu, não há o menor problema. Meu problema seria fazer um filme em um país do qual eu não falo a língua. Eu teria que fazer um filme tematizando o fato de que eu não sei a língua. Eu nunca fiz filmes com índios. Se um dia eu fizer - e vai ter um intérpreteeu vou tematizar a dificuldade de comunicação. Isso não tem nos filmes. Então eu acho que a diferença é um trunfo. Eu não faço um papel. Tenho um filme que chama Santa Marta, duas semanas no morro. É claramente um cara que vem de fora para fazer um filme. E o fato de declarar que é de fora faz, de certa forma, ficar de dentro. Um metalúrgico entrevistado por um metalúrgico dá coisas que eu não consigo, mas às vezes produz o mesmo do mesmo. Por isso é que sou contra o politicamente correto americano: só o gay pode filmar o gay, só o negro pode filmar o negro, só o anão pode filmar o anão. Sou pelo poder das minorias, mas jamais sem tratar do diferente. Meu sonho é que houvesse negros filmando o mundo dos brancos - aliás, filmando em geral já seria bom -, favelados filmando o mundo do asfalto e camponeses filmando cineastas. Eu não consigo fazer filmes sobre pessoas próximas a mim.

Numa relação de conversa há uma procura de uma igualdade utópica e provisória. Quando fui filmar o Cabra, um dos camponeses chamou: "Vamos tomar uma cachaça?".Eu disse: "Não quero".Seria o mesmo se o cara chamasse pra comer uma buchada. Eu não gosto de buchada. 
Nas ciências humanas, muitos pesquisadores participam longamente das comunidades que querem conhecer. $O$ sr., inversamente, prima pelo frescor do primeiro encontro. Poderia falar um pouco mais a esse respeito?

A etnografia é uma ciência. Um filme é cinema. Mas se ele tem alguma coisa ligada à etnografia é o fato de que eu faço de modo selvagem. Eu não conheço a pessoa antes da filmagem. Há um momento que dura meia hora a duas horas que é intenso e em que se dá a coisa. Depois, eu vou encontrar na pré-estreia e acaba. É o contrário do trabalho de algumas ciências. Mas há cineastas documentaristas europeus e americanos que vão, ficam seis meses, só filmam seis meses depois. Eu sou contra isso. Isso pode ser ótimo. Mas no meu caso, se eu vou conhecer a locação, conheço a pessoa e ela começa a me contar alguma coisa, eu falo: "Pelo amor de Deus, não me conte".Fico conversando "Bom dia, boa tarde, torceu o pé?", só digo bobagens.

Quando eu fui fazer o Cabra [na década de 1980], fiz uma viagem para ver se a Elizabeth estava viva. Fui à Galileia depois de dezessete anos sem ver aquela gente. Chego lá e encontro Zé Daniel, que era [na década de 1960] um garoto de dezoito anos e que guardou dois livros da equipe. Quando ele [nas filmagens da década de 1980] começou a me falar dos livros, eu estava sem a equipe: "Você guardou os livros... Que maravilhoso, mas não me conte mais nada". Quando eu vim com a câmera, falei: "E os livros?". Foi uma loucura. Foi rodado um rolo inteiro de filme. O essencial para mim é a primeira vez.

Em determinado momento da nossa conversa você perguntou como alguém consegue ver seus filmes. Permite que eu, que sou alguém que aguenta assisti-los, esboce uma resposta?

Tomo os exemplos de Babilônia 2000 e O fim e o princípio, filmes em que o sr. radicaliza a revelação das condições da filmagem. $O$ espectador acompanha a tal ponto a feitura do filme que acaba vivendo a angústia que é a sua diante da ameaça de não-realização de um documentário que, porém, já estamos assistindo. Trago esses exemplos, mas poderia citar outros em que a perspectiva do espectador quase que coincide com a sua. Ao mesmo tempo, não raramente o espectador se identifica com os entrevistados que tanto dizem sobre a condição humana. E, finalmente, não apenas continuamos a ser nós mesmos como somos lançados à reflexão. Talvez por isso haja quem aguente ver seus filmes...

E talvez por uma razão bem simples: você conhece o Brasil e fala a língua. Porque no Brasil se fala a mesma língua. Tirando 0,4\% de população indígena - e alguns falam o português - o resto é tolice. Claro que uma pessoa do Sul, que não conhece o Nordeste, leva um tempo para acostumar com a língua. Comparando com a Itália e seus dialetos, é espantosa a unidade da lín- 
gua no Brasil. E nessa nossa unidade, quando a língua que se fala no Nordeste parece estranha é porque eles empregam palavras do português arcaico que nós esquecemos. Não usam "restos", falam "sobejos"; para falar de certos tipos de pedras falam "seixos." Ninguém no Rio ou em São Paulo sabe o que quer dizer. Mas fora essas expressões regionais, existe uma grande unidade.

Mas o que você disse eu acho que está muito presente em Cabra. Quando eu vou procurar os filhos da Elizabeth Teixeira, vou nas casas, não sei se vou encontrar as pessoas. E aqueles que eu encontro, ligo a câmera e vamos lá. Então há um suspense que não é provocado. Não é Hitchcock. O espectador passa o que eu passo. Não estou sabendo o que vai acontecer.

O que você fala do Babilônia aconteceu porque foi filmado em um dia só e com cinco câmeras. É impessoal e tem um desespero de fazer no dia. E em O fim e o princípio eu queria fazer um filme no meio rural. Eu não sabia que o tema ia ser os velhos. Fomos para o fim da Paraíba para descobrir gente. A diferença é que seria impossível fazer o filme sem a mediação da Rosa [professora e moradora da região que levou a equipe ao encontro dos moradores]. Seria ingênuo acreditar que naquele mundo desconfiado, fechado, o filme sairia sem ela. Eu poderia fazer outro filme: "O fracasso de um filme," um road movie. Mas não esse filme.

Filmografia (Lins, 2004)

1978: Theodorico, imperador do sertão (16mm, cor, $49 \mathrm{~min}$.)

1964-1984: Cabra marcado para morrer (35mm, cor, $119 \mathrm{~min}$.)

1987: Santa Marta, duas semanas no morro (vídeo, 54 min.)

1989: Volta Redonda - Memorial da greve (vídeo, 42 min.)

1991: O fio da memória (16mm, 115 min.)

1992: Boca de lixo (vídeo, 50 min.)

1994: Os romeiros de Padre Cícero (vídeo, 38 min.)

1999: Santo Forte (35mm, 80 min.)

2001: Babilônia 2000 (35mm, 80 min.)

2002: Edifício Master (35mm, $110 \mathrm{~min}$.)

2004: Peões (35mm, $85 \mathrm{~min}$ )

2005: O fim e o princípio (35mm, $110 \mathrm{~min}$.)

2007: Jogo de cena (vídeo, 105 min.)

2009: Moscou (vídeo, 80 min.) 


\title{
The interview as a method: a talk with Eduardo Coutinho
}

\begin{abstract}
The name Eduardo Coutinho occupies central pages in the history of Brazilian documentary cinema. Known for interviews with anonymous people, his movies revolutionized the documentary production: they have helped to break the myth of the neutrality of the documentary and abolished the separation between the director and the characters. The modifications that his work produced at the aesthetics and epistemological fields particular to the cinema have relations with paradigm changes experimented by human sciences in the last century. This essay presents an interview with Eduardo Coutinho, where the film maker discusses the conception of reality present in his movies and the power of the cinema of transformation on men and society; mainly, he talks about the interviews, method in evidence in human sciences and in the cinema.
\end{abstract}

Keywords: Interview. Cinema. Ethnography. Social psychology.

\section{L'Entrevue comme méthode: un entretien avec Eduardo Coutinho}

Résumé : Le nom d’Eduardo Coutinho occupe les pages centrales dans I’histoire du cinéma documentaire brésilien. Connu par ses entrevues avec des personnes anonymes, ses films révolutionnèrent la production du genre: ils aident à mettre par terre le mythe de la neutralité des documentaires et ont défait la séparation entre le directeur et les personnages. Les transformations imprimées par son oeuvre dans les domaines aussi bien estéthiques qu'épistémologiques propres au cinéma ont des affinités avec les changements de paradigmes éprouvés par les sciences humaines au siècle dernier. Cet article présente une entrevue avec Eduardo Coutinho où le cinéaste discute la conception du réel présent dans ses filmes et le pouvoir de transformation du cinéma sur les hommes et la société. Mais surtout il discute l’Entrevue elle-même, méthode en évidence dans les sciences humaines et dans le cinéma.

Mots-clés: Entrevue. Cinéma. Etnographie. Psychologie sociale.

\section{La entrevista como método: una charla con Eduardo Coutinho}

Resumen:Eduardo Coutinho es nombre destacado en la historia del cine documental brasileño. Conocido por hacer entrevistas con personas anónimas, sus películas hicieron una revolución en el género del cine documental: ayudaran a demoler el mito de la neutralidad de las películas documentales y disolvieran la 
separación entre director y personajes. Las transformaciones que su obra determinó en el terreno de la estética y de la epistemología propia del cine tienen semejanzas con los cambios de paradigmas notados en las ciencias humanas en el siglo pasado. Este artículo presenta una entrevista con Eduardo Coutinho. En ella, el cineasta examina la concepción de realidad presente en sus películas, el poder de transformación del cine sobre hombres y sociedad; $y$, principalmente, habla sobre las entrevistas, método en foco en las ciencias humanas y en el cine.

Palabras clave: Entrevista. Cine. Etnografía. Psicología social.

\section{Referências}

Bernardet, J. C. (2003). Cineastas e imagens do povo. São Paulo: Companhia das Letras.

Bosi, E. (1995). Memória e sociedade: lembranças de velhos. São Paulo: Companhia das Letras.

Geertz, C. (1989). A interpretação das culturas. Rio de Janeiro: LTC.

Gonçalves Filho, J. M. (2003). Problemas de método em Psicologia Social: algumas notas sobre a humilhação política e o pesquisador participante. In A. M. B. Bock (Org.), Psicologia e o compromisso social (pp. 193-239). São Paulo: Cortez.

Lins, C. (2004). O documentário de Eduardo Coutinho: televisão, cinema e vídeo. Rio de Janeiro: Jorge Zahar.

Salles, J. M. (2004). Prefácio. In C. Lins, O documentário de Eduardo Coutinho: televisão, cinema e vídeo (pp. 7-10). Rio de Janeiro: Jorge Zahar.

Silva, V. G. (2005). Entre a poesia e o raio X: uma introdução à tendência pós-moderna na antropologia. In A. M. Barbosa \& J. Guinsburg (Orgs.), O pós-modernismo (pp. 145-158). São Paulo: Perspectiva.

Fernando Frochtengarten, Mestre e doutorando em Psicologia Social, Departamento de Psicologia Social e do Trabalho, Instituto de Psicologia da Universidade de São Paulo. Endereço para correspondência: Rua Senador César Lacerda Vergueiro, 471 ap 54 - Sumarezinho, 05435-060 - São Paulo - S.P. - Brasil, Telefone: 5511 3816-0405.Endereço eletrônico:fernandofrochtengarten@uol.com.br Meus sinceros agradecimentos ao Eduardo Coutinho pela atenção e o interesse a mim reservados.

Recebido em: 3/08/2007

Aceito em: 20/12/2007 